\title{
Korrespondenzen.
}

\section{Sport und Blinddarmentzündung?}

Von Herrn Prof. Dr. Albu geht uns folgende Zuschrift zu: Sehr geehrter Herr Kollege!

In weiten Laienkreisen ist, wie ich höre, eine Beunruhigung hervorgerufen durch einen vor einigen Wochen aus dem „Aerztlichen Vereinsblatt" in zahlreiche Tageszeitungen übergegangenen Aufsatz über die Verbreitung der Blinddarmerkrankungen in Preußen, welcher, auf Angaben der "Statistischen Korrespondenz" sich stützend, die auffällige Häufigkeit der Blinddarmentzündungen im jugendlichen Alter mit der zunehmenden Ausübung des Sports in Verbindung brachte. Da die Blinddarmerkrankungen augenblicklich der Schrecken des Publikums (und auch vieler Aerzte) sind, so erscheint es mir geboten, darauf hinzuweisen, daß der eben erwähnte, angeblich ursächliche Zusammenhang zwischen Sport und Blinddarmentzündung nur rein theoretisch konstruiert, ja vollkommen aus der Luft gegrifren ist, da in der ganzen medizinischen Literatur keinerlei Tatsachen vorliegen, welche auch nur die entfernte Berechtigung für die Annahme eines solchen Zusammenhanges darbieten. Nur der schon oft beklagte leidige Trugschluß: Post hoc, ergo propter hoc hat dazu verleitet, aus einzelnen zufälligen Beobachtungen allgemeine Folgerungen abzuleiten. Auch ich habe einmal den Fall erlebt, daß eine junge Dame nach einer durchtanzten Nacht eine schwere, leider tödlich verlaufene Blinddarmentzündung bekam; aber diese Patientin hatte, wie sich das in ähnlichen Fällen fast stets nachweisen läßt, schon einmal die gleiche Krankheit (einige Monate vorher) durchgemacht, sodaß also der Wurmfortsatz bereits als krankhaft verändert anzusehen war und wahrscheinlich bald bei irgend einer anderen Gelegenheit zu einem Anfall geführt hätte.

In der gerichtsärztlichen Praxis, in den Entscheidungen der Berufsgenossenschaften, der Schiedsgerichte des Reichsversicherungsamtes und der Lebensversicherungsgesellschaften ist es ein längst anerkannter Grundsatz, daß eine Blinddarmerkrankung bei einem ganz gesunden Menschen selbst durch einen den Bauch unmittelbar treffenden Unfall nicht hervorgerufen werden kann, da sie eine vom Blut oder häufiger vom Darm ausgehende Infektionskrankheit ist, für deren Ausbruch ein Unfall nur eine zufällige Gelegenheitsursache ist. Dieser Standpunkt, der in ärztlichen Gutachten und in der Literatur zu ungezählten Malen erörtert worden ist, kam auch neuerdings wieder allgemein zum Ausdruck bei der ausführlichen Debatte über die Ursache und die Entstehung der Blinddarmerkrankungen im Verein für innere Medizin.

Wenn diese Anschauung schon in Rücksicht auf direkte "Unfälle" gilt, um wie viel mehr berechtigt ist sie hinsichtlich einer fraglichen Einwirkung des Sports, die sich auf den Unterleib im allgemeinen doch nur durch Zerrung des Darms und seiner Nachbarschaft äußern könnte, niemals durch direkte, wenn auch nur stumpfe Verletzungen!

Unsere Jugend darf sich also getrost jeglichem Sport hingeben, ohne sich durch ein solches Gespenst schrecken zu lassen! Ja, ich möchte behaupten, daß eine energische Muskelarbeit, wie sie jeder ernstlich betriebene Sport mit sich bringt, eines der besten Mittel zur Verhütung der Blinddarmentzündung ist, insofern nämlich kräftige und ausgiebige Körperbewegungen erfahrungsgemäß die Darm. tätigkeit regeln, deren Vernachlăssigung eines der hauptsächlichsten disponierenden Momente für die Entstehung der Wurmfortsatzentzündungen ist. Wer aber einmal eine Blinddarmentzündung durchgemacht hat, der tut gut, danach sich für längere Zeit vom Sport fernzuhalten, damit die heilsamen frischen Verwachsungen des Wurmfortsatzes nicht zerrissen werden und zurückgebliebene Entzündungsprodukte ohne Störung sich aufsaugen können. Solche Belehrungen sollten die Hausärzte besorgten Eltern angesichts der jetzt entstandenen Beunruhigung en zuteil werden lassen!

Ihr sehr ergebener Albu. 